\section{Thinking small and thinking big}

\section{John Postgate}

Microcosmos: Four Billion Years of Microbial Evolution. By Lynn Margulis and Dorion Sagan. Summit, New York/Allen \& Unwin, London: 1986/1987. Pp.301. $\$ 17.95, £ 12.95$.

DESPITE the publisher's claims for originality and novelty, the message of this well-intentioned book has been familiar to biologists for much of the present century. It is that microbes play, and have played, a dominant role in the sustenance and development of the biosphere. Thus they are a crucial component of a resilient network of interactions among living things which maintains the chemical metastability of the geosphere, on which terrestrial life depends. Microbes help to buffer the geosphere such that it changes only slowly, roughly coordinately with the evolution of the biosphere. Indeed, they were the evolutionary precursors of macrobes, which demonstrably retain anatomical residua of their microbial ancestors; and evolution itself, which involves accretory, convergent and divergent pathways, has not ceased simply because man, a selfconscious, self-examining species, has emerged.

If I judge the authors' intention correctly, they wished to develop these concepts in a popular, palatable form, illustrated and revised in the light of knowledge acquired over the past few decades. For example, our own microbial residua are no longer seen to be just the leukocytes but include the ex-prokaryotic mitochondria; several other cell components probably stem from prokaryotes, and plant chloroplasts seem also to be of cyanobacterial origin; and there are hints that an endosymbiotic association between a eubacterium and an archaebacterial host was the progenitor of eukaryotic cells. We know that gene transfer is rampant among prokaryotes such that the whole Kingdom has access to a common gene pool and is thus capable of large evolutionary jumps. There is evidence that populations on the periphery of the biosphere (dry, cold, hot or saline regions) positively require the existence of the mainstream biota and function not only as foci of divergent evolution but also as reservoirs for repopulation after ecological calamity. And so on.

How far have Margulis and Sagan succeeded in their laudable endeavour? In my view not at all, because they have allowed their own enthusiasms, together with some naively simplistic statements of the views of others, to lead them into a counter-productive mish-mash of impre- cision and dramatic over-statement. For example, because we are derived from microbes, we are microbes: we are part of a "superorganism we call the microcosm" which is to become a "supercosm", ultimately to spread throughout the galaxy. The epithets of pulp science fiction abound: the "keen" perceptions of scientists have permitted "dazzling" advances; "spectacular" clues led to "astonishing" conquests with "staggering" implications for, amongst other things, how life coped with the "treacherous effect of light", or how "amazing" changes in oxygen tension left the biosphere "humming with the danger and thrill of free oxygen".

Oh my golly gosh! Such hyperbole might not matter if it did not lead to confusion. But metaphors and similes become hypotheses and theories, fact and speculation are deeply intertwined, anthropomorphisms and teleologies abound. Predictably the upshot is mysticism; try the following (p. 152):

\section{In the beginning}

Sarah Hargreaves

The Creation of Life: Past, Future, Alien. By Andrew Scott. Basil Blackwell: 1987. Pp.211. £14.95, \$19.95.

APART from the continuing resistance from Creationists, the evidence for the evolution of life on Earth is well accepted. But how did life begin? In this book, Andrew Scott sets out not to attempt to give his own answer to the question, but to provide a sober appraisal of the competing ideas and the sparsity of the facts on which those ideas are based.

The book begins with introductory descriptions of background physics, chemistry and biology. Scott then tackles the "standard" theory, which was given impetus by the experiments of Stanley Miller in the early 1950 s and which holds that life originated on Earth through the spontaneous reaction of organic compounds. This, according to Scott, is a "simplistic tale of the modern textbook and classroom" and he proceeds to identify its shortcomings. Although the basic constituents of living things could well have been abundant on the early Earth, there is no compelling indication that they were concentrated enough to generate nucleic acids and proteins; we have only sketchy evidence for the advent of replication, and that concerning the origin of the nucleic-acid-protein connection is even flimsier; finally, there is the question of the formation and evolution of the earliest cells, a process which no one has yet recreated in the laboratory.

What, then, are the alternatives? The following two chapters examine some
As tiny parts of a huge biosphere whose essence is basically bacterial we - with other life forms - must add up to a sort of symbiotic brain which it is beyond our capacity to comprehend or truly represent.

I smelled a deity there. And I was right. She duly emerged several chapters later as that embarrassing Earth Goddess called Gaia; this is the "supercosm" the authors have been preparing us for. Unhappily I am allergic to mysticism, whether it comes openly with prayer book or obfuscated with science. Yet the blurb and preface writers have found all this revelatory and it has the blessing of the Prophet Lovelock. Impressive erudition and much stimulating thought went into the authors' grandiose vision; I wish they had solved the problem of putting it into words scientifically.

John Postgate is Professor of Microbiology and Director of the Agricultural and Food Research Council Unit of Nitrogen Fixation, University of Sussex, Brighton BNI 9RQ, UK.

well-known possibilities. Greatest prominence is given to Graham Cairns-Smith's "low-tech" theory, according to which the earliest types of life were composed of inorganic, crystalline materials, able to replicate and evolve. These made possible the more familiar "high-tech" life forms based on nucleic acids, and were later taken over by them. Panspermia (the arrival of life on Earth from elsewhere), articulated by Arrhenius and later propounded by Francis Crick, also gets an airing, as does the view of Fred Hoyle and Chandra Wickramasinghe that interstellar space is full of life. Each of these ideas is discussed sympathetically and with consideration of how support for them might be obtained. Throughout, however, Scott sounds the proper notes of scepticism.

The discussion then turns to the development of complex organisms from the most basic of cells (with a brief and unsatisfactory foray into neurobiology) and the search for life elsewhere in the Universe. There is, too, a look to the future to the research prospects on the origin of life, and to the possibilities opened up by genetic engineering, and by robot and computer technology.

This is a book of questions rather than answers, and the author has not attempted to provide a definitive guide to his subject matter. At times, particularly in the last two chapters, he passes over some tantalizing points all too quickly, but a helpful list of further reading is provided for those who wish to delve further. The book is lucidly written and is illustrated with clear, straightforward diagrams. It will serve very well as an introduction for the nonscientist who is intrigued by the puzzles surrounding the origins of life.

Sarah Hargreaves is on the staff of Nature. 